\title{
Small Signal Modeling and Closed Loop Control Design of ZVS Current-fed Half-Bridge L-L Type Dc/Dc Converter with Active-Clamp
}

\author{
Akshay K. Rathore, Senior Member IACSIT, Ashoka K. S. Bhat, Fellow IEEE and Ramesh Oruganti, \\ Senior Member IEEE
}

\begin{abstract}
This paper presents the small signal model and closed loop control design using average current control for an L-L type active-clamped zero-voltage switching (ZVS) current-fed isolated DC-DC converter. State-space averaging technique is used to derive the small signal model. The controller is designed for fixed-frequency duty cycle modulation and works for wide input voltage and load variation. A complete design procedure is presented. Frequency response curves are obtained at different input voltage and load conditions to verify the stability and design, and to evaluate the performance of the controller. Simulation results for step changes in load are given to check the transient response of the converter.
\end{abstract}

Index Terms-Fuel cells, Small Signal Modeling, Closed Loop Control, DC-DC Converter, Zero-voltage switching.

\section{INTRODUCTION}

A high-frequency (HF) transformer isolated DC-DC converter is part of a fuel cell power conditioning system for standalone or utility interface [1][2] used to boost low fuel cell stack voltage (that can vary with fuel pressure [3]) higher than the peak of the grid or rated load voltage. This stepped up DC voltage is converted into line-frequency grid/load compatible AC power supply using an inverter stage [1-2]. Soft-switching is necessary to operate the converter at higher switching frequency to achieve small size, light weight and low cost converter. Although an active-clamped DC-DC current-fed converter and its analysis and design have been recently published [2][4-5], this converter can not maintain ZVS for wide variation in supply voltage and load variations. Therefore, a modified L-L type active-clamped current-fed ZVS DC-DC converter, shown in Fig. 1 has been proposed for this application [6]. This converter always operates with

Manuscript received September 20, 2009. This work was supported by a grant from the Natural Sciences and Engineering Research Council (NSERC) of Canada.

Akshay K Rathore is with the Department of Electrical and Computer Engineering, University of Illinois, Chicago, IL 60607 USA. (phone: 312-996-9548; e-mail: arathore@ uic.edu).

Ashoka K. S. Bhat is with Department of Electrical and Computer Engineering, University of Victoria, Victoria, BC V8W 3P6 Canada. (e-mail: bhat@engr.uvic.ca).

Ramesh Oruganti is with the Department of Electrical and Computer Engineering, National University of Singapore, Singapore (e-mail: eleramsh@nus.edu.sg). the duty cycle of main switches greater than $50 \%$ and in continuous current mode. The two main switches $S_{1}$ and $S_{2}$ are controlled by gating signals phase-shifted by $180^{\circ}$.

Auxiliary switches $S_{a 1}$ and $S_{a 2}$ are gated by signals complementary to main switch gating signals. The two inductors are identical but uncoupled to each other.

This front-end DC-DC converter should be controlled to produce a constant voltage at the input of the inverter for all fuel pressure values. This requires small signal modeling and closed loop control design of this converter and they are not yet reported in literature and therefore form the objectives of this paper. The peak current control requires slope compensation for stability and introduces error at high ripple currents at light load and high input voltage. Therefore, average current control of the two inductor currents is used in this paper. In literature, the current control of a single inductor and coupled inductor converter topologies are presented [7-10]. The current control of two independent (uncoupled) inductor topology was presented in [11] for active-clamped ZVS two-inductor current-fed isolated DC-DC converter. Detailed small signal analysis was presented while taking into account the effect of auxiliary clamp circuit [11] for ZVS. The series inductor current state variable was discontinuous (assuming high magnetizing inductance) and therefore, was omitted in the analysis. In the L-L type active-clamped current-fed isolated DC-DC converter presented in this paper, the series and parallel inductor carries continuous currents and add to the list of state variables in small signal analysis. It has been concluded in [11] that the effect of auxiliary clamp capacitor $C_{a}$ has negligible effect on frequency response (changing the phase margin by less than 2 degrees) but increases complexity in calculation and closed loop control design and is therefore, not considered as a state variable in the analysis, assuming voltage across it $\left(V_{C a}\right)$ constant.

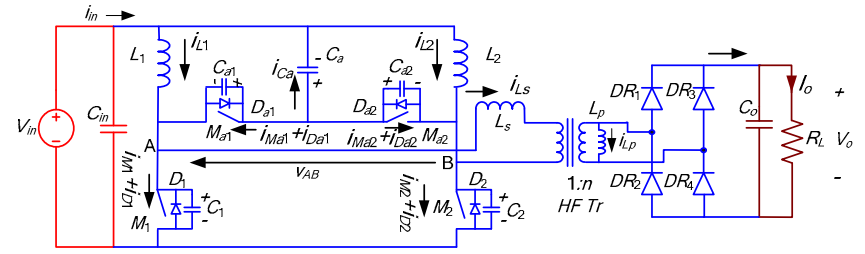

Fig. 1. Active-clamped L-L type current-fed isolated DC-DC converter.

The layout of the paper is as follows: Section II presents small signal analysis of the converter using state space 
averaging. Matrix form and transfer functions are derived. Closed loop control design of two loop average current control of the converter using 2 PI controllers is presented with a converter example rated at $200 \mathrm{~W}$ in Section III. Bode plots are drawn to verify the stability of two separate loops with and without controllers. The converter with the designed two-loop control system has been simulated in Section IV using PSIM 6.0.1 under full-load and 10\% load condition for two extreme input voltage conditions and frequency response curves for control-to-output are presented to verify the stability and design of the complete closed loop system. Also, the converter with designed controller has been simulated for step-change in load to verify the design of the closed loop control and to check the transient performance of the converter. The results verify the stability and design of the closed loop control system.

\section{Small Signal Modeling}

In this Section, small signal model of the converter is derived by averaging the state-space equations [12] for each interval of operation. Following assumptions made are in the analysis: 1) Inductors are identical, i.e., $L_{1}=L_{2}=L .2$ ) Charging and discharging intervals of the snubber capacitors are very small and neglected. 3) Leakage inductance of the transformer is part of $L_{s}$. 4) Magnetizing inductance is a part of parallel inductor $L_{p}$. 5) Voltage $v_{C a}$ across the auxiliary capacitor $C_{a}$ is assumed constant. 6) All the components are ideal and lossless. The operating waveforms with these assumptions are given in Fig. 2. The converter undergoes through 5 different intervals of operation in a HF half cycle as shown in Fig. 3. For the next HF half cycle, the intervals are repeated in the same sequence with other symmetrical devices conducting to complete the full HF cycle.

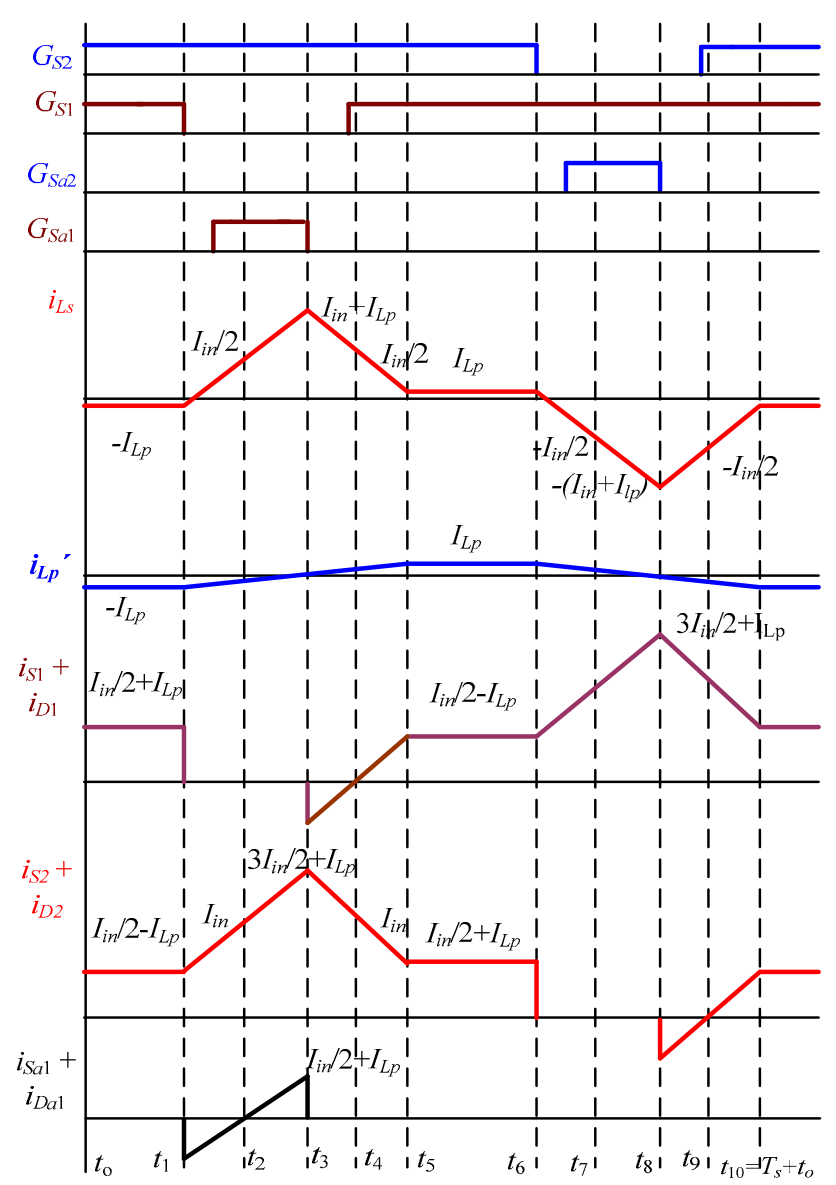

Fig: 2. Operating waveforms of the L-L type active clamped ZVS current-fed isolated DC-to-DC converter (Fig. 1).

The specifications and design values of the converter (Fig. 1) for illustration are [6]: Input voltage $V_{\text {in }}=22$ to $41 \mathrm{~V}$, output voltage $V_{\mathrm{o}}=350 \mathrm{~V}$, output power $P_{\mathrm{o}}=200 \mathrm{~W}$, switching frequency $f_{s}=100 \mathrm{kHz}, L=L_{1}=L_{2}=352 \mu \mathrm{H}, L_{s}=$ $4 \mu \mathrm{H}, L_{p}=1.6 \mathrm{mH}, C_{a}=1 \mu \mathrm{F}, C_{1}=C_{2}=0.6 \mathrm{nF}, C_{a 1}=C_{a 2}=$ $1.4 \mathrm{nF}, C_{\mathrm{o}}=1 \mu \mathrm{F} \mathrm{HF}$ (an electrolytic capacitor of $470 \mu \mathrm{F}$ is connected in parallel), turns ratio $n=4$ (secondary to primary).

Define: $d_{1} T_{\mathrm{s}}=t_{1}-t_{o}, d_{2} T_{\mathrm{s}}=t_{2}-t_{1}, d_{3} T_{\mathrm{s}}=t_{3}-t_{2}, d_{4} T_{\mathrm{s}}=t_{4}-t_{3}, d_{5} T_{\mathrm{s}}$ $=t_{5}-t_{4}, d_{6} T_{\mathrm{s}}=t_{6}-t_{5}, d_{7} T_{\mathrm{s}}=t_{7}-t_{6}, d_{8} T_{\mathrm{s}}=t_{8}-t_{7}, d_{9} T_{\mathrm{s}}=t_{9}-t_{8}, d_{10} T_{\mathrm{s}}=$ $t_{10}-t_{9}$.

The duty cycle of the main switches (including conduction of the anti-parallel diode) are defined as

$d_{S 1}=d_{1}+d_{4}+d_{5}+d_{6}+d_{7}+d_{8}+d_{9}+d_{10}$

$d_{S 2}=d_{1}+d_{2}+d_{3}+d_{4}+d_{5}+d_{6}+d_{9}+d_{10}$

The turn-off durations of the main switches are

$d_{S 1}{ }^{\prime}=1-d_{S 1}=d_{2}+d_{3}, \quad d_{S 2}{ }^{\prime}=1-d_{S 2}=d_{7}+d_{8}$

The discharging durations of supply inductor are

$d_{S 1} "=d_{4}+d_{5}, \quad d_{S 2} "=d_{9}+d_{10}$

Five state variables defined for the small signal modeling of the converter are: 1) Currents through the boost inductors $i_{L 1}$ and $i_{L 2} .2$ ) Transformer or series inductor current $i_{L s} .3$ ) Parallel inductor current $i_{L p}$. 4) Output voltage $v_{o}$.

State equations are written for each interval of operation based on the equivalent circuits shown in Fig. 3 and is presented next. 


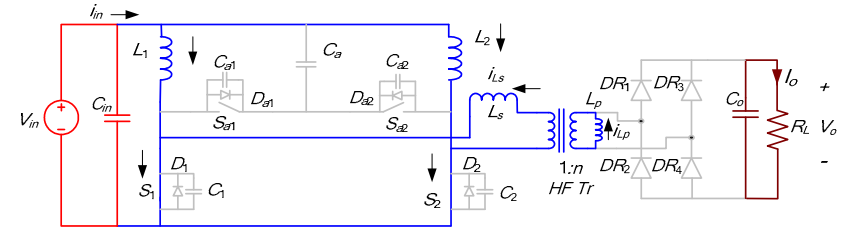

(a) Interval 1: $t_{0}<t<t_{1}$

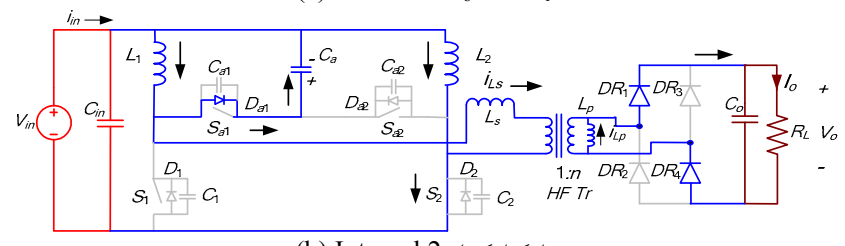

(b) Interval 2: $t_{1}<t<t_{2}$

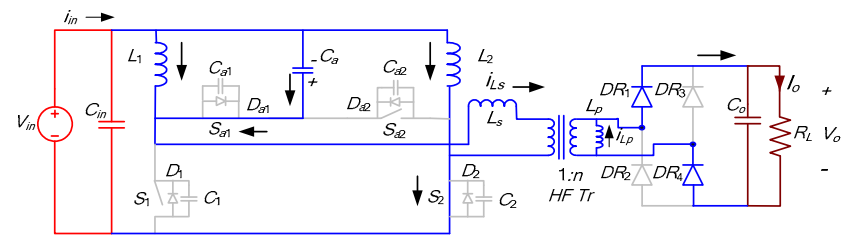

(c) Interval 3: $t_{2}<t<t_{3}$

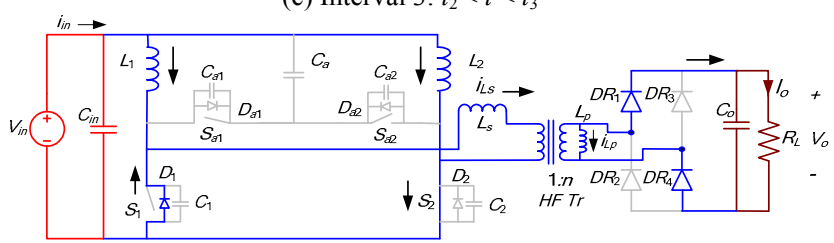

(d) Interval 4: $t_{3}<t<t_{4}$

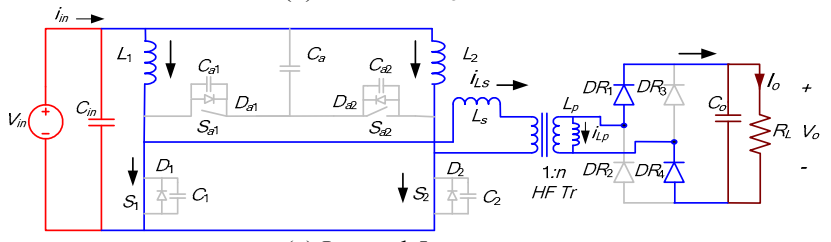

(e) Interval 5: $t_{4}<t<t_{5}$

Fig. 3. Equivalent circuits during different intervals of operation of the converter for the waveforms shown in Fig. 2.

Interval $1\left(t_{0}<t<t_{1}\right)$ : Both the main switches $S_{1}$ and $S_{2}$ are ON. Inductors $L_{1}$ and $L_{2}$ are storing energy and power is transferred to the load by the filter capacitor $C_{0}$. Constant current flows through the series tank inductor $L_{s}$ and parallel inductor $L_{p}$. The state equations for this interval are

$L \frac{d i_{L 1}}{d t}=v_{i n}, L \frac{d i_{L 2}}{d t}=v_{i n}, L_{S} \frac{d i_{L s}}{d t}=0, L_{p} \frac{d i_{L p}}{d t}=0$,

$C_{o} \frac{d v_{O}}{d t}=-\frac{v_{O}}{R_{L}}$

Interval $2\left[t_{1}<t<t_{2}\right]: S_{1}$ is turned off and the anti-parallel body diode $D_{a 1}$ of auxiliary switch $S_{a 1}$ starts conducting. A voltage $\left(v_{i n}+v_{C a}-v_{o} / n\right)$ appears across the series inductor $L_{s}$. Output voltage $v_{o}$ appears across the parallel inductor $L_{p}$ and current through it starts increasing. The rectified current charges the output capacitor $C_{o}$ through rectifier diodes $D R_{1}$ and $D R_{4}$ and power is transferred to the output. The state equations for this interval are

$L \frac{d i_{L 1}}{d t}=-v_{C a}, L \frac{d i_{L 2}}{d t}=v_{\text {in }}, L_{s} \frac{d i_{L s}}{d t}=v_{\text {in }}+V_{C a}-\frac{v_{o}}{n}$,

$L_{p} \frac{d i_{L p}}{d t}=v_{o}, C_{o} \frac{d v_{O}}{d t}=\frac{i_{L S}}{n}-\frac{v_{o}}{R_{L}}$

Interval $3\left[t_{2}<t<t_{3}\right]$ : Auxiliary switch $S_{a 1}$ is turned on with ZVS. Currents $i_{L S}$ and $i_{L p}$ increase with the same slope. At the end of this interval, auxiliary switch $\mathrm{S}_{\mathrm{a} 1}$ is turned-off.
The same equations of interval 2 hold good for this interval too.

Interval $4\left[t_{3}<t<t_{4}\right]$ : Anti-parallel diode $D_{1}$ of main switch $S_{1}$ starts conducting. The current $i_{L S}$ decreases with a negative slope of $\left[V_{\mathrm{o}} /\left(n L_{S}\right)\right]$ and $i_{L p}$ increases with the same slope.

$L \frac{d i_{L 1}}{d t}=v_{\text {in }}, L \frac{d i_{L 2}}{d t}=v_{\text {in }}, L_{S} \frac{d i_{L S}}{d t}=-\frac{v_{o}}{n}, L_{p} \frac{d i_{L p}}{d t}=v_{o}$,

$C_{o} \frac{d v_{O}}{d t}=\frac{i_{L s}}{n}-\frac{v_{O}}{R_{L}}$

Interval $5\left[t_{4}<t<t_{5}\right]$ : Switch $S_{1}$ is turned ON with ZVS. At the end of this interval, $i_{L s}$ reaches a constant value and switch current is equal to $i_{L 1}$. The same equations of interval 4 hold good for this interval too.

Equations for the other half cycle can be written using symmetry. State equations are averaged over a HF cycle to model the converter and after simplification results (using (1) to (3)) in the following equations:

$$
\begin{gathered}
L\left\langle\frac{d i_{L 1}}{d t}\right\rangle=\left(d_{S 1}\right) \cdot v_{i n}-\left(1-d_{S 1}\right) \cdot V_{C a} \\
L\left\langle\frac{d i_{L 2}}{d t}\right\rangle=\left(d_{S 2}\right) \cdot v_{i n}-\left(1-d_{S 2}\right) \cdot V_{C a} \\
L_{S}\left\langle\frac{d i_{L s}}{d t}\right\rangle=\left(V_{C a}+v_{i n}-\frac{v_{o}}{n}\right) \cdot\left(-d_{S 1}+d_{S 2}\right)-\frac{v_{o}}{n} \cdot\left(d_{S 1}^{\prime \prime}-d_{S 2}^{\prime \prime}\right) \\
L_{p}\left\langle\frac{d i_{L p}}{d t}\right\rangle=v_{o} \cdot\left(-d_{S 1}+d_{S 2}+d_{S 1}^{\prime \prime}-d_{S 2}^{\prime \prime}\right) \\
C_{O} \cdot\left\langle\frac{d v_{C o}}{d t}\right\rangle=\left(\frac{i_{L s}}{n}-i_{L p}\right)_{r e c t, a v}-\frac{v_{O}}{R_{L}}
\end{gathered}
$$

where the average output rectified current is given by

$$
\begin{aligned}
& \left(\frac{i_{L s}}{n}-i_{L p}\right)_{\text {rect }, a v}=\frac{1}{n}\left[i_{L 1} \cdot\left(1-d_{S 1}+d_{S 1}^{\prime \prime}\right)+i_{L 2} \cdot\left(1-d_{S 2}+d_{S 2}^{\prime \prime}\right)\right] \\
& +\frac{v_{o} \cdot T_{S}}{2 \cdot L_{p}} \cdot\left[\left(1-d_{S 1}+d_{S 1}^{\prime \prime}\right) \cdot d_{S 1}^{\prime \prime}+\left(1-d_{S 2}+d_{S 2}^{\prime \prime}\right) \cdot d_{S 2}^{\prime \prime}\right]
\end{aligned}
$$

Also, equating peak-to-peak current through $L_{s}$ and $L_{p}$, following equations can be obtained:

$\left[\left(v_{i n}+V_{C a}-v_{o} / n\right) / L_{S}\right] \cdot\left(1-d_{S 1}\right)=\frac{v_{o}}{n \cdot L_{S}} \cdot d_{S 1}^{\prime \prime}+\frac{n \cdot v_{o}}{L_{p}} \cdot\left(1-d_{S 1}+d_{S 1}^{\prime \prime}\right)$

$\left[\left(v_{i n}+V_{C a}-v_{o} / n\right) / L_{S}\right] \cdot\left(1-d_{S 2}\right)=\frac{v_{o}}{n \cdot L_{S}} \cdot d_{S 2}^{\prime \prime}+\frac{n \cdot v_{o}}{L_{p}} \cdot\left(1-d_{S 2}+d_{S 2}^{\prime \prime}\right)$

Introducing perturbation around the steady state values (represented by capital letters) for the state variables and other quantities such that $i_{L 1}=I_{L}+\hat{i}_{L 1}, i_{L 2}=I_{L}+\hat{i}_{L 2}, v_{\text {in }}=V_{\text {in }}+\hat{v}_{\text {in }}, v_{o}=V_{o}+\hat{v}_{o}$,

$d_{S 1}=D+\hat{d}_{S 1}, d_{S 2}=D+\hat{d}_{S 2} \cdot d_{S 1}{ }^{\prime \prime}=D^{\prime \prime}+\hat{d}_{S 1}{ }^{\prime \prime}$, $d_{S 2}{ }^{\prime \prime}=D^{\prime \prime}+\hat{d}_{S 2}{ }^{\prime \prime}, d_{1}=D_{1}+\hat{d}_{1}, d_{2}=D_{2}+\hat{d}_{2}, d_{3}=D_{3}+\hat{d}_{3}$, $d_{4}=D_{4}+\hat{d}_{4}, d_{5}=D_{5}+\hat{d}_{5}, d_{6}=D_{6}+\hat{d}_{6}, d_{7}=D_{7}+\hat{d}_{7}$, $d_{8}=D_{8}+\hat{d}_{8}, d_{9}=D_{9}+\hat{d}_{9}, d_{10}=D_{10}+\hat{d}_{10}$ where $D=$ duty cycle of the main switches $=$ $D_{1}+D_{4}+D_{5}+D_{6}+D_{7}+D_{8}+D_{9}+D_{10}=D_{1}+D_{2}+D_{3}+D_{4}+D_{5}+D_{6}$ $+D_{9}+D_{10}$

$D^{\prime \prime}=$ discharging duration of series inductor $=D_{4}+D_{5}=$ $D_{9}+D_{10}$.

After introducing perturbation in (7)-(14), comparing $\mathrm{AC}$ quantities, while neglecting the second order terms, then taking Laplace transform and eliminating $\hat{d}_{S 1}{ }^{\prime \prime}(s)$ and $\hat{d}_{S 2}{ }^{\prime \prime}(s)$ 
(using (13) and (14)) results in the following equations in matrix form

$\hat{x}(s)=A^{-1}(s) \cdot B_{1}(s) \cdot \hat{d}_{S 1}(s)+A^{-1}(s) \cdot B_{2}(s) \cdot \hat{d}_{S 2}(s)+A^{-1}(s) \cdot B_{3}(s) \cdot \hat{v}_{i n}(s)$

where

$\widehat{x}(s)=\left[\begin{array}{c}\hat{i}_{L 1}(s) \\ \hat{i}_{L 2}(s) \\ \hat{i}_{L s}(s) \\ \hat{i}_{L p}(s) \\ \hat{v}_{o}(s)\end{array}\right] \quad A^{-1}(s)=\left[\begin{array}{ccccc}\frac{1}{s L} & 0 & 0 & 0 & 0 \\ 0 & \frac{1}{s L} & 0 & 0 & 0 \\ 0 & 0 & \frac{1}{s L_{s}} & 0 & 0 \\ 0 & 0 & 0 & \frac{1}{s L_{p}} & 0 \\ a_{51} & a_{52} & 0 & 0 & a_{55}\end{array}\right]$

$B_{1}(s)=\left[\begin{array}{c}V_{i n}+V_{C a} \\ 0 \\ -\left\{V_{i n}+V_{C a}-\frac{(a+1) \cdot V_{O}}{n}\right\} \\ -(a+1) \cdot V_{o} \\ -\left(K_{2}+a \cdot K_{3}\right)\end{array}\right] \quad B_{2}(s)=\left[\begin{array}{c}0 \\ V_{i n}+V_{C a} \\ \left.V_{i n}+V_{C a}-\frac{(a+1) \cdot V_{O}}{n}\right\} \\ (a+1) \cdot V_{o} \\ -\left(K_{2}+a \cdot K_{3}\right)\end{array}\right]$

$B_{3}(s)=\left[\begin{array}{c}D \\ D \\ 0 \\ 0 \\ 2 b \cdot K_{3}\end{array}\right], a_{51}=a_{52}=\frac{\left(1-D+D^{\prime \prime}\right)}{s \operatorname{Ln}\left(K_{1}+2 c K_{3}\right)}$,

$a_{55}=\frac{1}{s C_{o}+K_{1}+2 c K_{3}}, K_{2}=\frac{V_{o} \cdot T_{S}}{2 L_{p}} \cdot D^{\prime \prime}+\frac{I_{L}}{n}$

$K_{1}=\left(\frac{1}{R_{L}}-\frac{T_{S}}{L_{p}} \cdot D^{\prime \prime} \cdot\left(1-D+D^{\prime \prime}\right)\right), K_{3}=\frac{V_{O} \cdot T_{S}}{2 L_{p}} \cdot\left(1-D+2 D^{\prime \prime}\right)+\frac{I_{L}}{n}$

$a=\left[a_{1} / L_{S}-n V_{o} / L_{p}\right] /\left[\left(a_{2}\right) V_{o}\right], b=(1-D) /\left[\left(L_{S}\right)\left(V_{o}\right)\left(a_{2}\right)\right]$,

$c=\left(1-D+D^{\prime \prime}\right) / V_{o}, a_{1}=V_{c a}+V_{i n}-V_{o} / n, a_{2}=1 /\left(n L_{s}\right)+n / L_{p}$

\section{A. Control-to-output transfer function}

From (15), the control-to-output transfer function is found by setting $\hat{v}_{\text {in }}=0$. It results in the following equation

$\frac{\hat{v}_{o}(s)}{\hat{d}_{S 1}(s)+\hat{d}_{S 2}(s)}=\frac{\left(K_{2}+a \cdot K_{3}\right) \cdot\left[\frac{\left(1-D+D^{\prime \prime}\right)}{n \cdot L} \cdot \frac{\left(V_{i n}+V_{C a}\right)}{\left(K_{2}+a \cdot K_{3}\right)}-s\right]}{s \cdot\left(s C_{o}+K_{1}+2 \cdot c \cdot K_{3}\right)}$

Substituting the values of $200 \mathrm{~W}$ converter in (16) gives

$\frac{\hat{v}_{o}(s)}{\hat{d}_{S 1}(s)+\hat{d}_{S 2}(s)}=\frac{(3191.5) \cdot(12663.62-s)}{s \cdot(s+7.84)}$

The bode plot of the control-to-output transfer function given by (17) is shown in Fig. 4. The phase margin (PM) of the uncompensated control-to-output transfer function is negative and is equal to $-30.2^{\circ}$ that makes the system unstable when small disturbances are introduced.

\section{CONTROLLER DESIGN}

Fig. 5 shows the complete two-loop feedback control system of the average current controlled DC-DC converter using 2 PI controllers and 2 modulators having the same values of frequency and amplitude but phase shifted by $180^{\circ}$. The design of the two control loops are given separately.

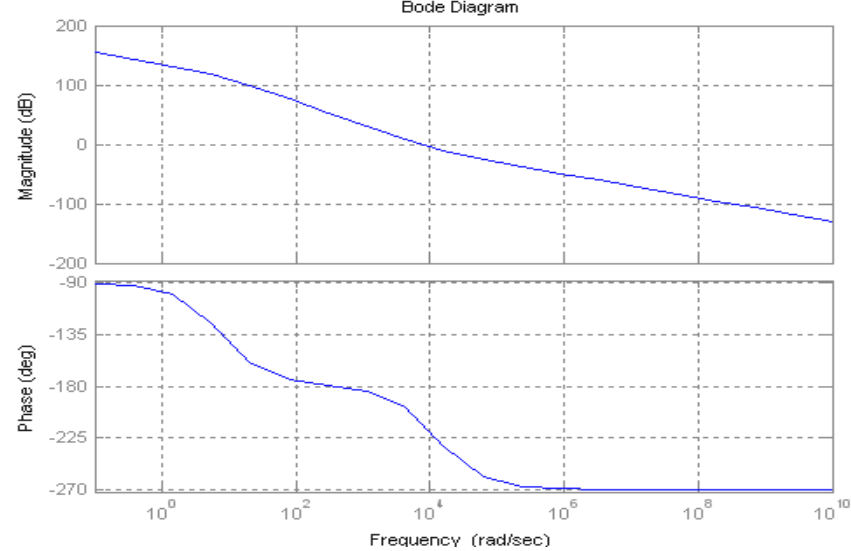

Fig. 4. Bode plot of control-to-output transfer function of uncontrolled system.

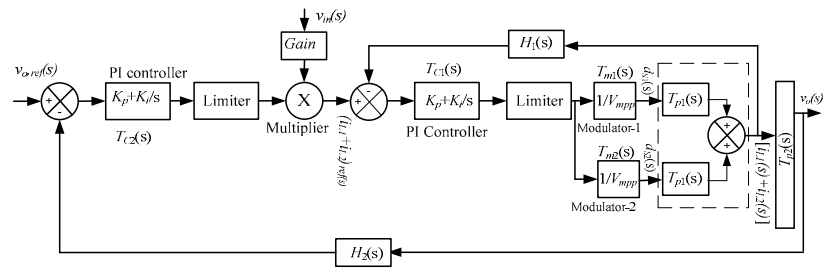

Fig. 5. Two-loop closed loop current controlled system.

\section{A. Design of current control loop}

The inner current control loop is shown in Fig. 6. The current controller design involves defining the current-loop quantitatively and then designing the controller to achieve certain design criteria of phase margin and bandwidth [13-15]. First, control to inductor current transfer function is derived. Then the PI controller design is presented. Only one PI controller controls the $I_{L 1}+I_{L 2}$.

$$
\begin{gathered}
T_{p 1}(s)=\frac{\hat{i}_{L 1}(s)}{\hat{d}_{S 1}(s)}=\frac{\hat{i}_{L 2}(s)}{\hat{d}_{S 2}(s)}=\frac{\left(V_{i n}+V_{C a}\right)}{s \cdot L} \\
T_{p 1}(s)=\frac{314285.7}{s}
\end{gathered}
$$

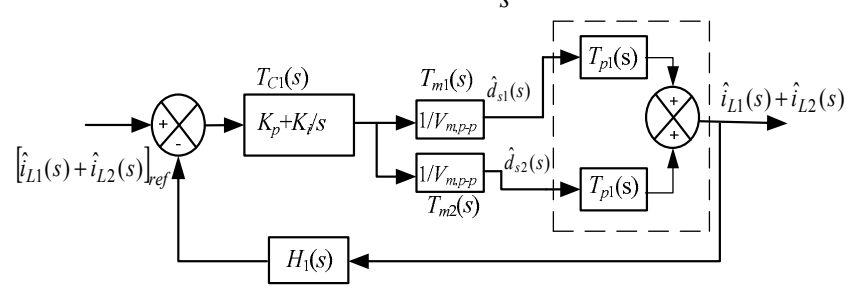

Fig. 6. Current control loop with PI controller.

Equation (19) defines the small signal transfer function between duty cycle and inductor current. Assuming an efficiency $\eta=90 \%$, the total average inductor currents $I_{L 1}+$ $I_{L 2}=P_{\mathrm{o}} /\left(V_{i n} . \eta\right)=10.1 \mathrm{~A}$. Selecting inductor current reference $\left(I_{L 1}+I_{L 2}\right)_{\text {,ref }}=10 \mathrm{~V}$, feedback gain $H_{1}(s)=10 / 10.1 \approx 1$. The open loop transfer function of current control loop results in PM of $90^{\circ}$ at cross over frequency of $99.43 \mathrm{krads} / \mathrm{sec}$. A PI controller is designed to meet the criteria of $\mathrm{PM}=60^{\circ}$ [13-15] at crossover frequency $f_{c}=15.92 \mathrm{kHz}$ [15] to reduce the steady state error and control the average inductors' current.

A triangle wave is selected as modulating signal. The frequency of the modulating signals is same as the switching frequency $(100 \mathrm{kHz})$. Here, $T_{m}(s)=T_{m 1}(s)=T_{m 2}(s)$. The 
maximum slope of the inductor current is $V_{C a} / L$. For minimum input voltage of $22 \mathrm{~V}$ and $D=0.8, V_{C a}$ is equal to $88 \mathrm{~V}$. In half of the triangle period $\left(T_{S} / 2\right)$, the current ripple reaches a value, equal to peak-to-peak value of the triangular modulating signal and is given by

$$
V_{m, p-p}=\frac{V_{C a}}{L} \cdot \frac{T_{s}}{2} \cdot K_{m f}
$$

where $K_{m f}$ is a multiplying factor and its value is $1 \mathrm{~V} / \mathrm{A}$ for the hall effect current sensor used and here $V_{m, p-p}=1.257 \mathrm{~V}$. Giving some tolerance for noise etc., peak-to-peak value of the triangle wave chosen is $V_{m, p-p}=2.5 \mathrm{~V}$. Then the modulator transfer function $T_{m}(\mathrm{~s})=1 / V_{m, p-p}=0.4$. Transfer function of the PI controller is

$$
T_{C}(s)=K_{p}+\frac{K_{i}}{s}=\frac{K_{p}\left(s+K_{i} / K_{p}\right)}{s}
$$

Open loop transfer function of the current-loop is given by

$$
T_{O L 1}(\mathrm{~s})=2 \cdot T_{C}(\mathrm{~s}) \cdot T_{m}(\mathrm{~s}) \cdot T_{p 1}(\mathrm{~s}) \cdot H_{1}(\mathrm{~s})
$$

The power stage transfer function $T_{p 1}(\mathrm{~s})$ is given by (19).

Substituting the values in (22) gives

$$
T_{O L 1}(s)=(99431.8)\left(\frac{K_{p}\left(s+K_{i} / K_{p}\right)}{s^{2}}\right)
$$

The requirement is that the PM should be $60^{\circ}$ at the gain cross over frequency $f_{c}=15.92 \mathrm{kHz}$ or $\omega_{c}=100 \mathrm{krad} / \mathrm{sec}$, where $\mathrm{PM}=180^{\circ}$ - phase angle of the loop. Therefore phase angle of the current-loop $T_{O L 1}(\mathrm{~s})=180^{\circ}-\mathrm{PM}=120^{\circ}$.

$$
\angle T_{O L 1}(s)=180^{\circ}-\tan ^{-1}\left(\frac{\omega_{c}}{K_{i} / K_{p}}\right)=120^{\circ}
$$

We get $K_{i} / K_{p}=57733.23$. The time constant of the integrator, $\mathrm{s} T=K_{p} / K_{i}=17.32 \mu \mathrm{s}$. The magnitude of the open loop transfer function $T_{O L 1}(\mathrm{~s})$ should be equal to 1 at the gain cross over frequency $f_{c}=15.92 \mathrm{kHz}$ or $\omega_{c}=100 \mathrm{krad} / \mathrm{sec}$.

$$
\left|(99431.8) \cdot \frac{K_{p}\left(s+K_{i} / K_{p}\right)}{s^{2}}\right| \omega_{c}=1
$$

Using $s=j \omega$ in (23), $K_{p}=0.871$. Fig. 7 shows the Bode plot of the current control loop with PI controller. The phase margin is $59.84^{\circ}$ at cross over frequency of $101.7 \mathrm{krad} / \mathrm{sec}$ and shows high gain at low frequencies.

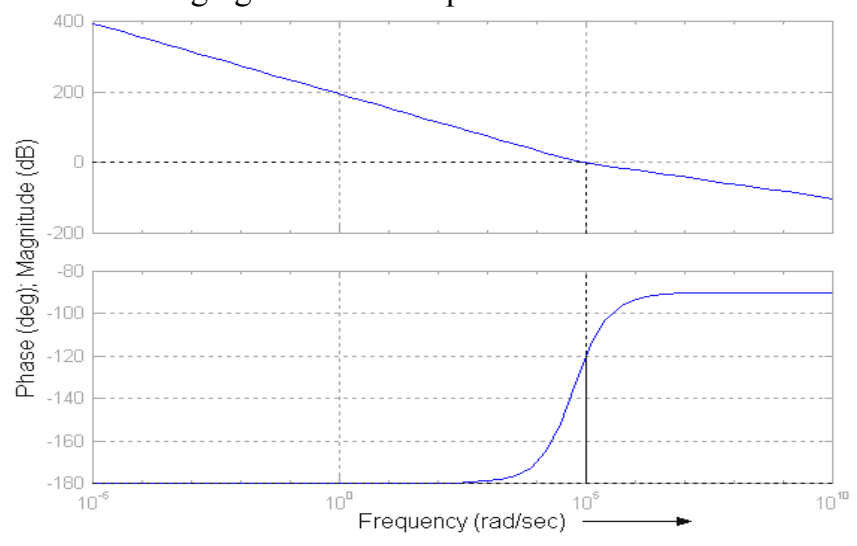

Fig. 7. Bode plot of current control loop with controller.

\section{B. Design of voltage control loop}

The voltage loop, shown in Fig. 8, generates the inductor current reference $\left(I_{L 1}+I_{L 2}\right)_{\text {ref }}$ for the inner current loop. Transfer function between output voltage and sum of inductors' currents is

$$
T_{p 2}(s)=\frac{\hat{v}_{o}(s)}{\hat{i}_{L 1}(s)+\hat{i}_{L 2}(s)}=\frac{1}{n} \cdot \frac{\left(1-D+D^{\prime \prime}\right)}{\left(s C_{o}+K_{1}+2 \cdot c \cdot K_{3}\right)}
$$

Substituting the values of the converter parameters in (26)

$$
T_{p 2}(s)=\frac{128.6}{(s+7.86)}
$$

Equation (27) defines the small signal transfer function between output voltage and inductor current and is used as power stage transfer function $T_{p 2}(\mathrm{~s})$ to design the voltage loop. Fig. 9 shows the bode plot of voltage control loop without PI controller. The phase margin is $90^{\circ}$ for frequencies above $1637.3 \mathrm{rad} / \mathrm{sec}$. The low frequency gain is very low.

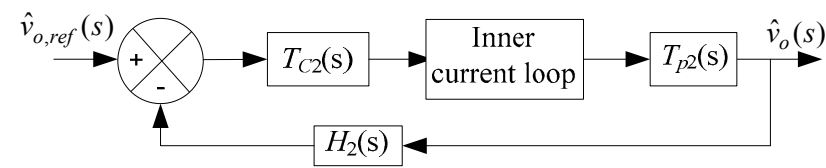

Fig. 8. Outer voltage control loop.

The bandwidth of the voltage loop is set at $100 \mathrm{~Hz}$. The low frequency gain needs to be increased while maintaining a minimum PM of $60^{\circ}$. Open loop transfer function of voltage control loop is

$$
T_{O L 2}(\mathrm{~s})=T_{C}(\mathrm{~s}) \cdot T_{p 2}(\mathrm{~s}) \cdot H_{2}(\mathrm{~s})
$$

Selecting voltage reference $V_{o, r e f}=5 \mathrm{~V}$, feedback gain $H_{2}(s)=5 / 350 \approx 0.0143$. Substituting the values in (28)

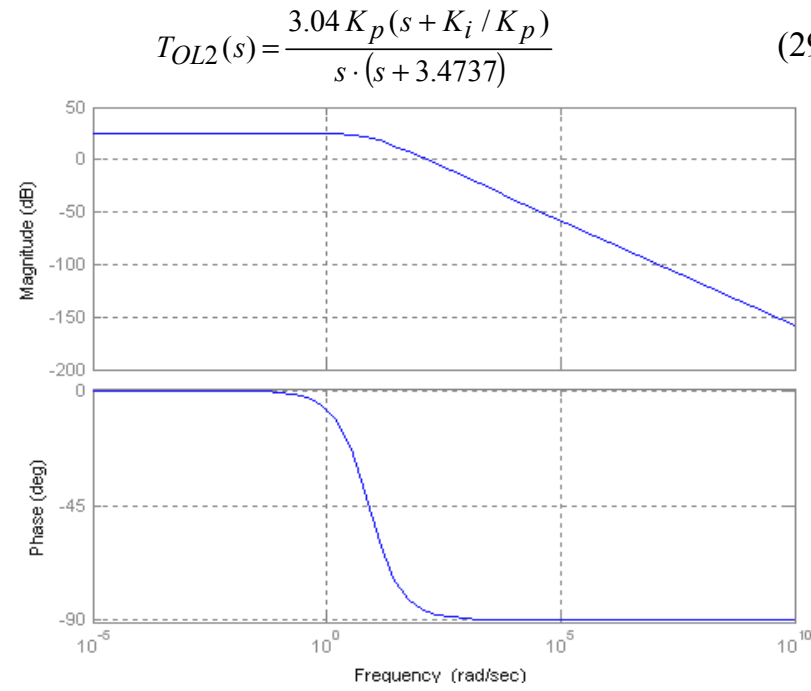

Fig. 9. Bode plot of voltage control loop without controller.

Following the same method described for inner current loop design, the calculated values are $K_{i} / K_{p}=377.53 ; K_{p}=$ 177.17. The time constant of the integrator, $\mathrm{s} T=K_{p} / K_{i}=2.65$ ms. Fig. 10 shows the Bode plot of the voltage control loop with PI controller. The low frequency gain is boosted-up and the $\mathrm{PM}$ is $59.21^{\circ}$ at crossover frequency of $635.85 \mathrm{rad} / \mathrm{sec}$. The outer voltage control loop is stable and achieves required $\mathrm{PM}$ at pre-set cross-over frequency. 


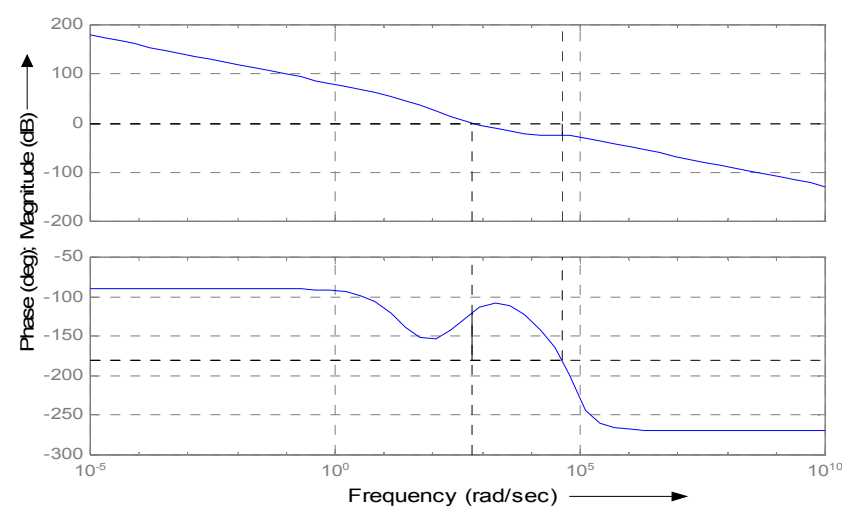

Fig. 10. Bode plot of voltage control loop with PI controller.

\section{FREQUENCY RESPONSE CURVES AND SIMULATION RESULTS}

The stability of the control system and the controller design are verified by plotting the frequency response curves of control-to-output transfer function by simulating the converter with the designed controller using PSIM 6.0.1 for input voltages of 22 and $41 \mathrm{~V}$ at full, half and $10 \%$ load (sample plots are shown in Fig. 11 and 12).

It was observed that the PM for the given conditions is between 58 to 71 degrees and therefore it can be concluded that the closed loop control system is stable for the entire given operating range of input voltage and from full load down to light load. There is a slight difference in the crossover frequencies but acceptable. The simulation was done for a few discrete frequency points and the time scale for simulation was $0.1 \mu$ s (to reduce the simulation time with reasonably good accuracy) and may not be sufficient for creating a smooth curve. This may be a possible reason.

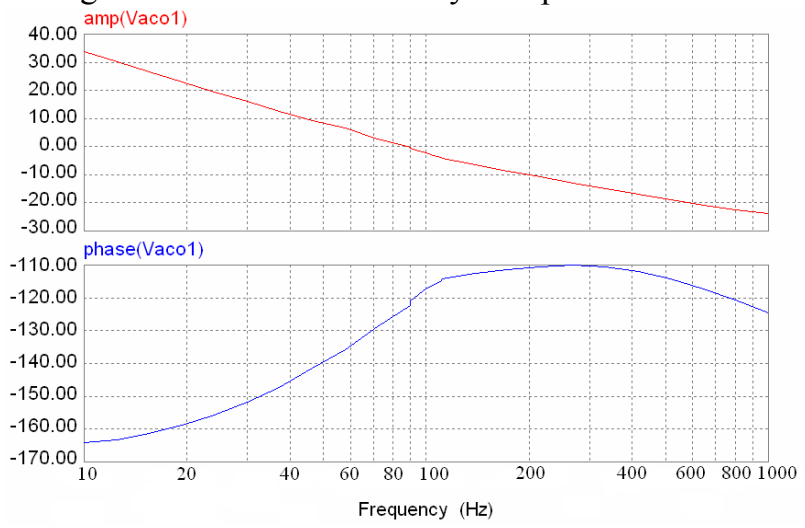

(a)

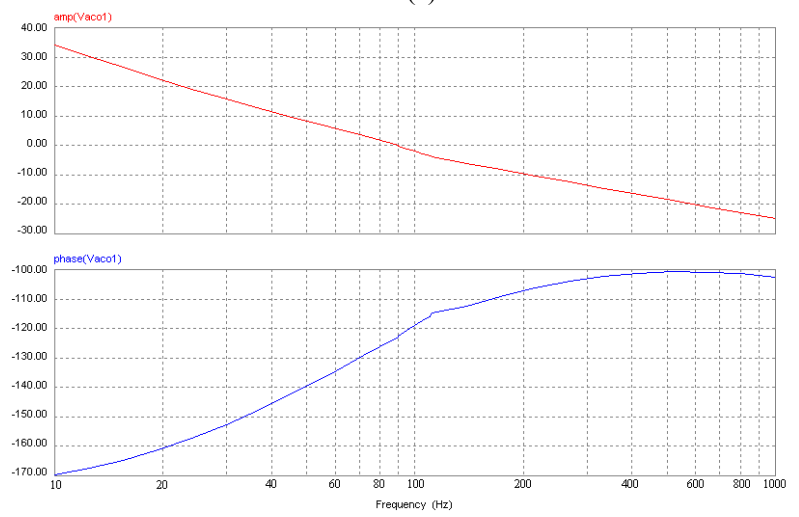

(b)
Fig. 11. Frequency response curves of closed loop control system (control to output) obtained from PSIM simulation for different load conditions at input voltage of $22 \mathrm{~V}$ (a) Full load: $\mathrm{PM}=60^{\circ}$ and crossover frequency $=90$

$\mathrm{Hz}$, (b) $10 \%$ load: $\mathrm{PM}=58^{\circ}$ and crossover frequency $=90 \mathrm{~Hz}$.

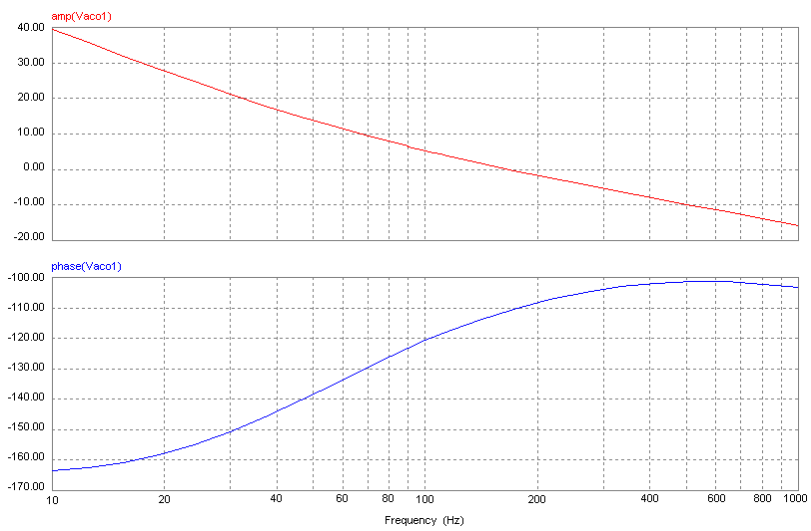

(a)
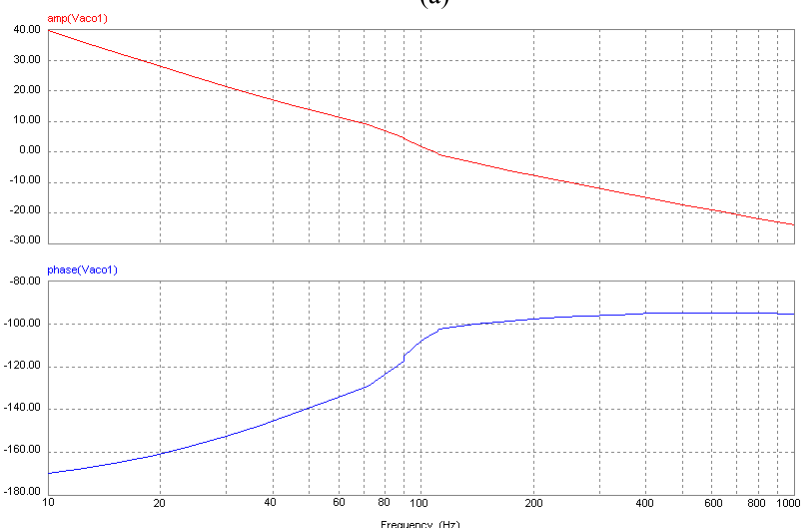

(b)

Fig. 12. Frequency response curves of closed loop control system (control to output) obtained from PSIM simulation for different load conditions at input voltage of $41 \mathrm{~V}$ (a) Full load: $\mathrm{PM}=68^{\circ}$ and crossover frequency $=168 \mathrm{~Hz}$., (b) $10 \%$ load: $\mathrm{PM}=76^{\circ}$ and crossover frequency $=108$ $\mathrm{Hz}$.

Fuel cells are very sensitive to input current ripples. For stable and continuous operation of the fuel cells and therefore of the power converter, the average input current should be controlled to be dc, which requires that bandwidths of voltage and current loops are separated far apart with a slow voltage loop and a fast current loop [16]. The drawback with slow voltage loop is high ripple voltage, which is acceptable for an inverter load [16]. Also, a difference in bandwidths of voltage and current loops has been proposed [17-20] to introduce time scale separation in their dynamics, which is then utilized to make approximations to simplify the design and discussed in [11]. Current-mode control is preferred for fuel cell system [21].

Simulation results using PSIM 6.0.1 to check the transient performance of the converter for step change in load when driven by the designed closed loop controller are shown in Figs. 13 and 14 for input voltage of 22 and $41 \mathrm{~V}$, respectively. Simulation results show that DC-DC converter output voltage overshoot and undershoot are less than $1 \mathrm{~V}$ for step change in load keeping the voltage constant at the intermediate DC link or input of the next inverter stage. Similarly the overshoot and undershoot in the inductor currents is always less than $1 \mathrm{~A}$ from their next steady state value for step change in load. Also, the fuel cell input current does not show a sudden high overshoot but it changes 
smoothly to the next steady state value. The settling time is around $20 \mathrm{~ms}$. The sudden change in load causes a jump in switch voltage and current during transient operation but these values are within safe limiting values of the switches' ratings due to the limiters and the converter continues its safe operation.

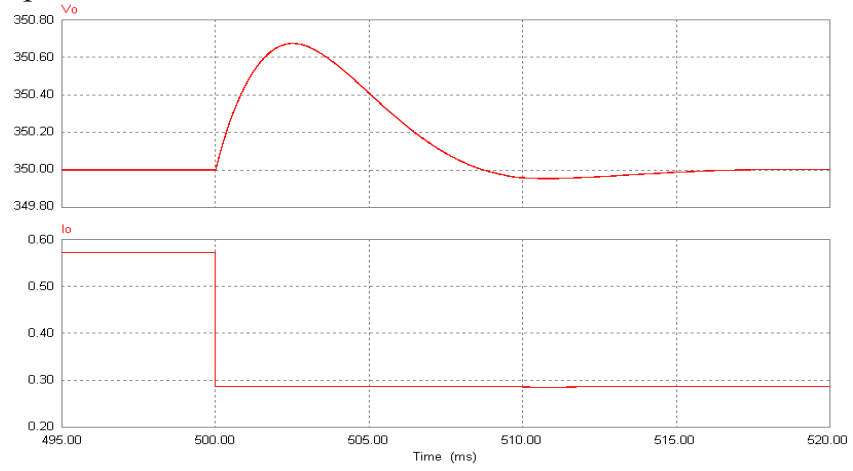

(a) $v_{\mathrm{o}}=$ output voltage; $i_{\mathrm{o}}=$ output current

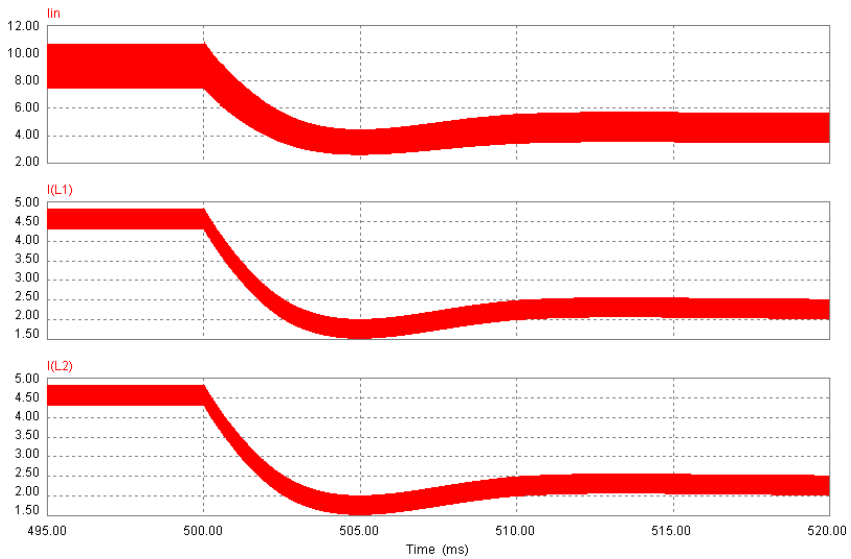

(b) $i_{\text {in }}=$ input current; $i_{L 1}=$ inductor $L_{1}$ current; $i_{L 2}=$ inductor $L_{2}$ current

Fig. 13. Simulation waveforms of two-loop average current controlled L-L type active-clamped current-fed DC-DC converter with $V_{\text {in }}=22 \mathrm{~V}$ and step load change from full load to half load at $\mathrm{t}=0.5 \mathrm{~s}$.

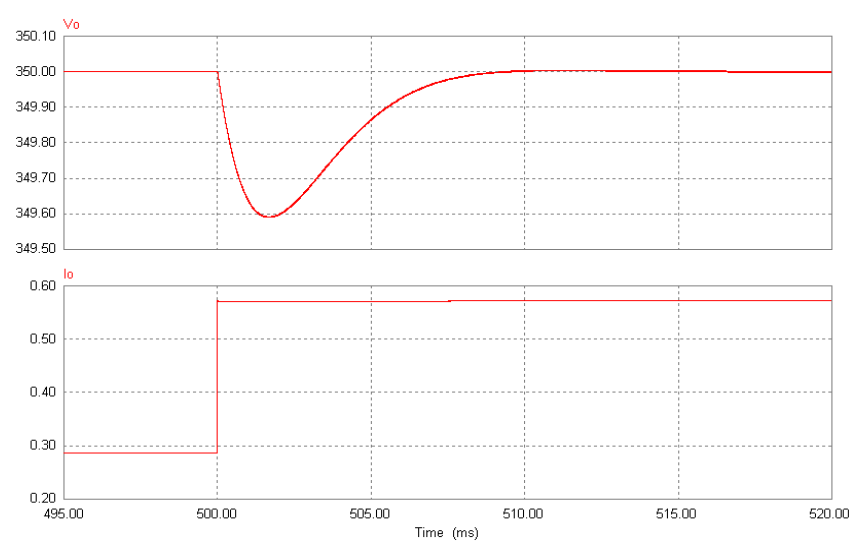

(a) $v_{0}=$ output voltage; $i_{0}=$ output current

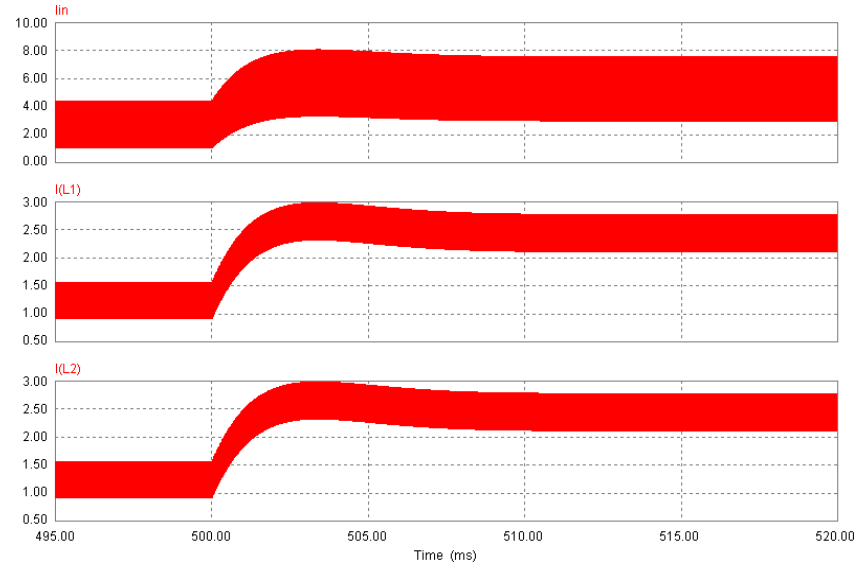

(b) $i_{\text {in }}=$ input current; $i_{L 1}=$ inductor $L_{1}$ current; $i_{L 2}=$ inductor $L_{2}$ current

Fig. 14. Simulation waveforms of two-loop average current controlled L-L type active-clamped current-fed DC-DC converter with input voltage $\mathrm{V}_{\text {in }}=$

$41 \mathrm{~V}$ and step load change from half load to full load at $\mathrm{t}=0.5 \mathrm{~s}$.

Small signal analysis and average current control of standard two-inductor active-clamped current-fed converter was presented in [11]. This topology [11] has discontinuous series inductor current $i_{L s}$ (assuming high magnetizing inductance or no parallel inductor) and therefore, was omitted and simplified the analysis. But the series inductor current at light load is not sufficient to discharge the snubbers to maintain ZVS of main switches [11]. In the proposed L-L type active-clamped current-fed isolated DC-DC converter, the series and parallel inductor carries continuous currents and add to the list of state variables in small signal analysis. This increases the complexity of the analysis (size of matrix in (15)) but the available current in series inductor aided by parallel inductor, provides the energy to discharge the snubber capacitors across the switches and maintains ZVS of main switches at light load for the complete wide input voltage range. This has been illustrated by simulation waveforms in Figs. 15-16 at $V_{\text {in }}=41$ for step load change from full-load to half- load at $t=0.5 \mathrm{~s}$.

Fig. 15 shows that L-L type active-clamped current-fed converter maintains ZVS during the transient duration. It exhibits ZVS in steady-state condition as well. On the contrary, standard active-clamped -fed converter enters into hard-switching region and main switches loose ZVS during transients as well as in steady-state as shown in Fig. 16.

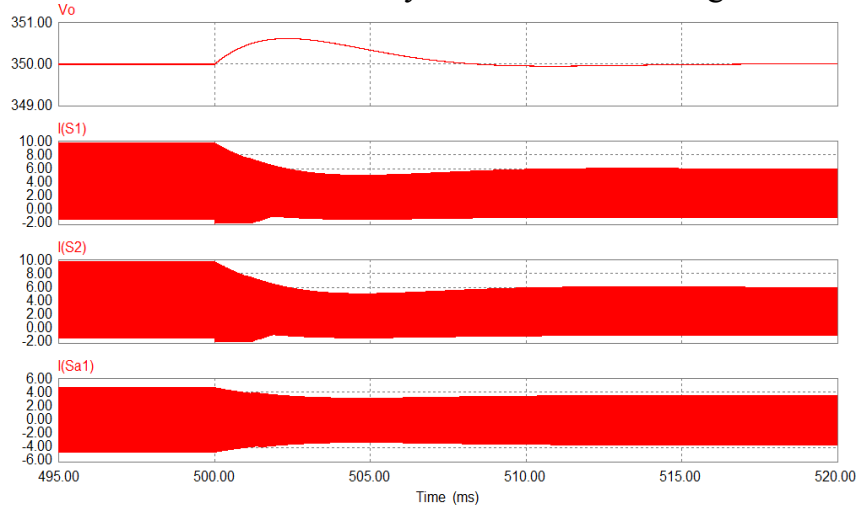

(a) 


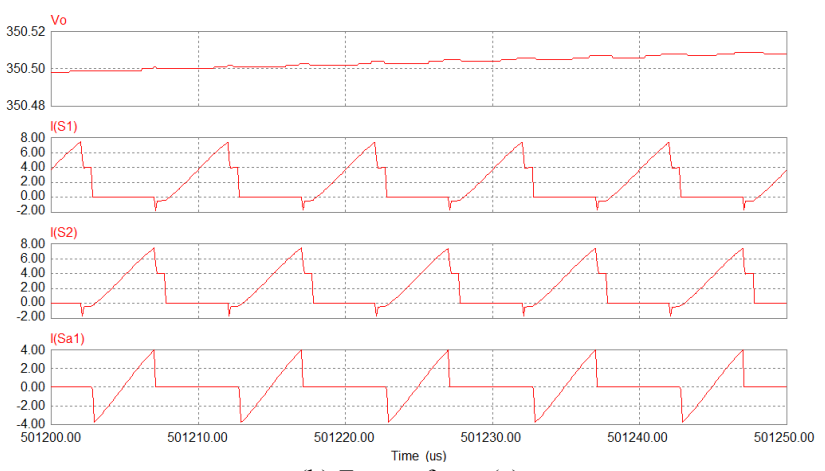

(b) Zoom of part (a)

Fig. 15.Simulation waveforms of two-loop average current controlled L-L type active-clamped current-fed DC-DC converter at $V_{\text {in }}=41$ for step load change from full-load to half- load at $t=0.5 \mathrm{~s}$.

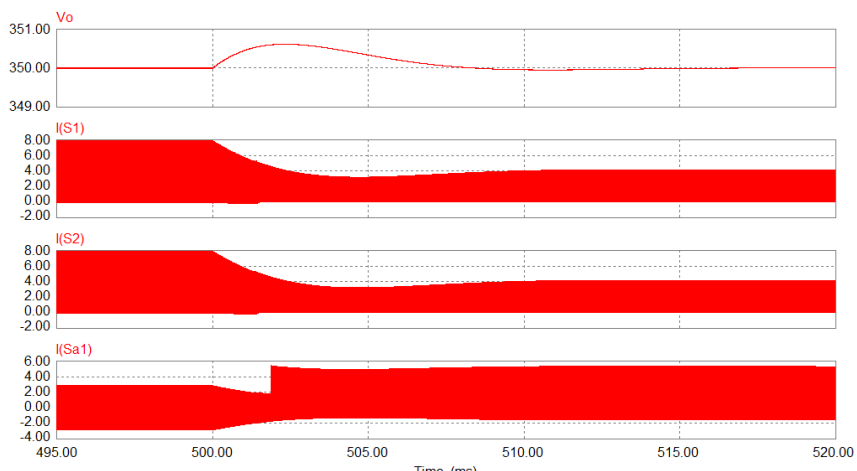

(a)

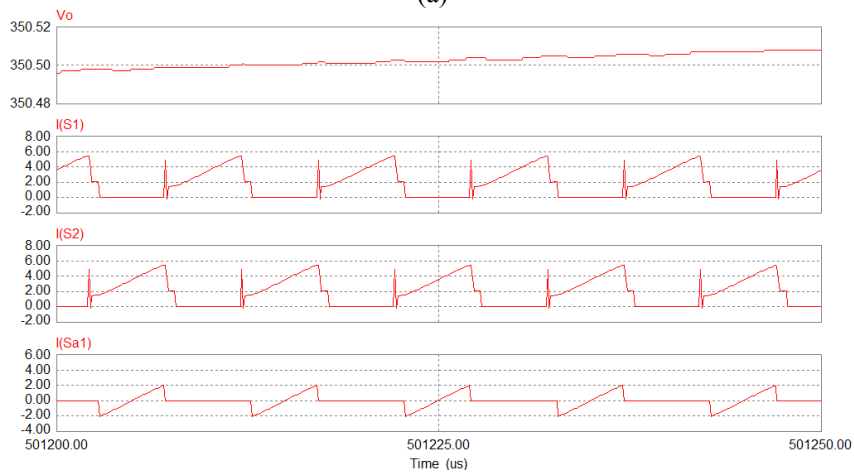

(b) Zoom of part (a)

Fig. 16. Simulation waveforms of two-loop average current controlled standard current-fed DC-DC converter at $V_{\text {in }}=41 \mathrm{~V}$ for step load change from full-load to half- load at $t=0.5 \mathrm{~s}$.

\section{CONCLUSION}

Small signal modeling and transfer functions of the L-L type active-clamped current-fed isolated DC-DC converter are derived using state-space averaging. A complete step-by-step closed-loop control design for average current control has been presented. The two boost inductor currents are controlled independently by controlling the total inductor currents using one PI controller and two modulators. The two modulating signals used for fixed frequency duty cycle modulation have the same amplitude and frequency but shifted in phase by $180^{\circ}$. The reference input for the current control loop is generated by an outer voltage loop. Frequency response curves have been presented. The converter with designed controller is stable for wide operating conditions of input voltage and load variations.

\section{REFERENCES}

[1] A. K. Rathore, A. K. S. Bhat and R. Oruganti, "A Comparison of Soft-Switched DC-DC Converter for Fuel Cell to Utility Interface Application," IEEE Power Conversion Conf., Japan, 2007, pp. 588-594.

[2] A. K. Rathore, A. K. S. Bhat and R. Oruganti, "Analysis and Design of Active-Clamped ZVS Current-fed DC-DC Converter for Fuel Cell to Utility-Interface Application," IEEE International Conference on Industrial and Information Systems, Sri Lanka, 2007, pp. 503-508.

[3] P. T. Krein, R. S. Balog and X. Geng, "High-frequency link inverter for fuel cells based on multiple-carrier PWM," IEEE Transactions on Power Electronics, Vol. 19, No. 5, September 2004, pp. 1279-1288.

[4] S. Han, H. Yoon, G. Moon, M. Youn, Y. Kim and K. Lee, “A new active clamping zero-voltage switching PWM current-fed half-bridge converter," IEEE Transactions on Power Electronics, Vol. 20, No. 6, pp. 1271-1279, 2005.

[5] S-J. Jang, C-Y Won, B-K. Lee and J. Hur, "Fuel cell generation system with a new active-clamping current-fed half-bridge converter," IEEE Transactions on Energy Conversion, Vol. 22, No. 2, pp. 332-340, 2007.

[6] A. K. Rathore, "High-Frequency Transformer Isolated Power Conditioning Unit for Fuel cells to Utility Interface Application," $P h D$ Dissertation, University of Victoria, Victoria, BC, Canada, 2008.

[7] M. Veerachary, T. Senjyu, and K. Uezato, "Modeling of closed-loop voltage-mode controlled interleaved dual-boost converter," International Journal on Computers and Electrical Engineering, Vol. 29, pp. 67-84, 2003 (www.elsevier.com/locate/compeleceng).

[8] C. Sudhakar Babu, and M. Veerachary, "Predictive valley current control for two inductor boost converter," IEEE International Symposium on Industrial Electronics, Vol. 2, pp. 727-731, June 2005.

[9] S. Dwari, S. Jayawant, T. Beechner, S. K. Miller, A. Mathew, M. Chen, J. Riehl, and J. Sun, "Dynamics characterization of coupled inductor boost DC-DC converters," IEEE Workshop on Computers in Power Electronics, pp. 264-269, July 2006.

[10] Y. Jang, and M. M. Jovanovic, "New two-inductor boost-converter with auxiliary transformer," IEEE Transactions on Power Electronics, vol. 19, pp. 169-175, 2004.

[11] A. K. Rathore, A. K. S. Bhat, S. Nandi and R. Oruganti, "Closed Loop Control Design of Two-Inductor Current-Fed Isolated DC-DC Converter for Fuel Cells to Utility Interface Application," IEEE IAS Annual Meeting, Conf. CD, Alberta, Canada, Oct. 2008.

[12] R. Severns and G. Bloom, Modern DC-to-DC Switchmode Power Converter Circuits, Van Nostrand Reinhold Co. New York 1985.

[13] R. W. Erickson, "Fundamentals of Power Electronics," Second Edition, 2000, Kluwer Academic Publishers (Book).

[14] N. Mohan, T. Undeland, and W. P. Robbins, Power Electronics Converters, Applications and Design, John Wiley \& Sons Inc., 2003.

[15] L.Dixon, "Average Current Mode Control of Switching Power Supplies," Unitrode Power Supply Design Seminar, 1990.

[16] J.-S. Lai, S.-Y. Park, S. Moon and C.-L. Chen, "A High Efficiency 5-kW Soft-Switched Power Conditioning System for Low Voltage Oxide Fuel Cells," IEEE Power Conversion Conference (PCC). Nagoya, Japan, 2007, pp. 463-470.

[17] S. Wall, "Fast controller design for single-phase power-factor correction systems", IEEE Transactions on Industrial Electronics, Vol. 44, No. 5, pp. 654-660, October 1997.

[18] K. De Gusseme, D. M. Van De Sype and J. A. A. Melkebeek, "Design issues for digital control of boost power factor correction converters," IEEE International Symposium on Industrial Electronics, pp. 731-736, 2002.

[19] S. Bibian and H. Jin, "High performance predictive dead-beat digital controller for DC power supplies," IEEE Transactions on Power Electronics, Vol. 17, No. 3, pp. 420-426, May 2002.

[20] R. Erickson, M. Madigan and S. Singer, "Design of a simple high-power-factor rectifier based on the flyback converter," IEEE Applied Power Electronics Conference and Exposition, pp. 792-801, March 1990.

[21] Y. Wang, S. Choi, and E. Lee, "Efficient and ripple-mitigating dc-dc converter for residential fuel cell system," International Journal on Electrical Power and Energy Systems, Vol. 31, pp. 43-89, 2009 (www.elsevier.com/locate/ijepes). 


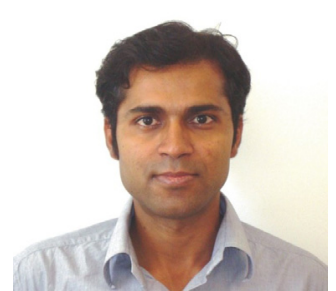

Akshay K Rathore was born in Rajasthan, India on 08 Dec 1979. He received his B.E. in Electrical Engineering from Maharana Pratap University of Agriculture and Technology, Udaipur, India in 2001, M.Tech. in Electrical Machines and Drives from Institute of Technology, Banaras Hindu University (IT-BHU), Varanasi, India in 2003 and PhD in Power Electronics from University of

Victoria, BC, Canada in 2008.

He worked as a Lecturer in Electrical Engineering from Feb, 2003-Aug. 2004 in India in College of Technology and Engineering Udaipur and Mody Institute of Technology and Science (Deemed University), Lakshamangarh, India. He has been a Sessional Lecturer in Department of Electrical and Computer Engineering at University of Victoria, BC, Canada from May-Dec 2007. From Sept. 2008 to Aug. 2009, he was a research fellow at Electrical machines and Drives research Lab, University of Wuppertal, Germany. Presently he is working as a postdoctoral research associate at University of Illinois at Chicago, IL, USA. His research interests include soft-switching techniques for high-frequency power conversion, power conversion for distribution generation and renewable energy systems, linear induction motor, closed loop control of switch mode power supplies, optimal pulsewidth modulation and control of motor drives.

Dr. Rathore has been listed in Marquis Who's Who in Science and Engineering in 2006, Who's Who in the World, and Who's Who in America in 2008. He is a reviewer of IEEE Transactions on Power Electronics, Industrial Electronics and Industry Applications. He is also a reviewer of IET (UK), Elsevier, Francys \& Taylor and IACSIT Journals.

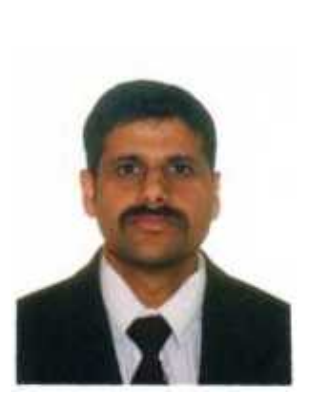

Ashoka K. S. Bhat received the B.Sc. degree in physics and math from Mysore University, Mysore, India, in 1972. He received the B.E. degree in electrical technology and electronics, and the M.E. degree in electrical engineering, both with distinction from the Indian Institute of Science, Bangalore, in 1975 and 1977, respectively. He also received the M.A.Sc. and $\mathrm{Ph} . \mathrm{D}$. degrees in electrical engineering from the University of Toronto, Canada, in 1982 and 1985, respectively. From 1977 to 1981, he worked as a Scientist with the Power Electronics Group, National Aeronautical Laboratory, Bangalore, and was responsible for the completion of a number of research and development projects. After working as a Postdoctoral Fellow for a short time, he joined the Department of Electrical and Computer Engineering, University of Victoria, BC, Canada, in 1985, where he is currently a Professor and is engaged in teaching and conducting research in the area of power electronics. He was responsible for the development of the Electromechanical Energy Conversion and Power Electronics courses, and laboratories in the Department of Electrical Engineering, University of Victoria.

Dr. Bhat received the excellence in Teaching Award from the Faculty of Engineering during the year 2008. He is a Fellow of IEEE (USA), Life Fellow of IETE (India), and a Registered Professional Engineer in the province of BC, Canada.

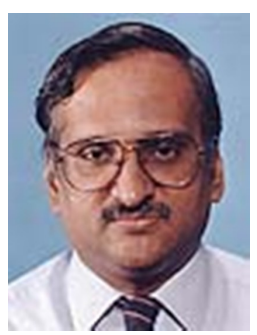

Ramesh Oruganti received the B.Tech. and M.Tech. degrees from the Indian Institute of Technology, Madras, India, in 1969 and 1972, respectively, and the Ph.D. degree from Virginia Polytechnic Institute and State University, Blacksburg, USA in 1987.

He worked for several years in India in the area of power conversion before receiving the Ph.D. degree. Following this, he was with the Corporate R\&D Division, General Electric Company, Fairfield, CT, working on advanced power-converter systems. Since 1989, he has been with the Department of Electrical and Computer Engineering, National University of Singapore, Singapore, where he is currently an Associate Professor. He has authored several papers in power electronics. He is the holder of a patent on dc-dc converters. He has been active in research on several areas of power electronics. More recently, his research interest is in renewable energy applications of power electronics.

Dr. Oruganti is a senior member of IEEE (USA) and was the recipient of two prize paper awards. 